\title{
A Case Study of Volkswagen Unethical Practice in Diesel Emission Test
}

\author{
Nazanin Mansouri \\ HELP University \\ Kuala Lumpur, Malaysia
}

\begin{abstract}
By end of 2015, automotive industry was shocked by an unethical action of Volkswagen which is one of the noticeable market players amongst automakers. Since October 2015 this case has been under investigation by various authorities. The investigators have managed to find out significant factors leading to this emission scandal. Volkswagen deceptive scandal has resulted in a series of overwhelming devastating consequences on direct and indirect stakeholders of Volkswagen. Since this case is still ongoing, the judge has not succeeded to finalize the case and deliver Volkswagen penalties.

In this case, the participants and primary reasons of this rigging in diesel emission test are identified in line with previous studies. Moreover, the critical impacts of such deception on Volkswagen stakeholders are explained in details. The proposals which are given to the judge to consider an appropriate deal to Volkswagen are discussed in details. Last but not least, in order to prevent such scandal to take place in the future, recommendations are provided.
\end{abstract}

Keywords: Volkswagen emission test, Volkswagen deception, EPA standard, Environmental agency

\section{INTRODUCTION}

In the recent decades conservation and sustainable environment are of great concern to the nations. The natural phenomenon such as globalization and also environment pollutions such as emission have been considered by a great number of environmental protection agencies and united nation agencies. A noticeable attention to conservation and saving green have led Environmental Protection Agency (EPA) tighten emission control because of harmful and mortal effects of nitrogen oxide which is a pollutant found in car's exhaust (Klier, \& Linn, 2016). Therefore, since 1970s EPA has announced continuously more restrictions on standard of emission for light-duty vehicles entailing small pickup trucks, automobiles, and sport-utility cars. The most stringent requirements for emission standards were for vehicle models of year 2004 (Klier, \& Linn, 2016). Not only EPA but also federal agency created significant diminution (94\%) in the amount of emitted nitrogen oxide by vehicles tailpipe from 1.25 to 0.07 grams per mile (Klier, \& Linn, 2016). Emitted nitrogen oxide endangers human lives and triggers disease such as asthma, respiratory, cardiovascular, bronchitis, and pre-mature death.

The new emission standard posed immense hardship to automakers manufacturing fuel-efficient diesel cars to the United States automobile market. One of the market players in automobile industry is Volkswagen attempting to crack the United States diesel market; as a result, Volkswagen became a substantial seller in automaker market. Volkswagen competitors namely Honda, Hyundai, Mazda, and Nissan found new emission standards significantly challenging; therefore, they made decision to scrap their tactics (Davenport, \& Hakim, 2016).

Surprisingly, in the years 2015, Volkswagen was announced as "diesel dupe" in virtue of rigging emission test to make diesel vehicles seem emitting less pollution than what they really emit (Clothier, 2015). In September 2015 it was reported by EPA that in an ample number of Volkswagen vehicles, sold in worldwide, a defeat device or software was embedded in diesel engine with the purpose of changing vehicle performance to improve required result. Volkswagen aimed at pretending that its vehicles follow emission standards; therefore, conducted emission test in the lab instead of on the roads (Le Page, 2015). Volkswagen cars were programmed to detect the situation where cars with TDI diesel engines experience emission test and then take information from brakes, accelerator, and steering. Subsequently, the program made slight changes to engine setting with the purpose of diminishing nitrogen oxide level emitted by Volkswagen diesel cars. The actual result of Volkswagen emission test on road was thirty-five (35) times more than cheated result in the lab (Le Page, 2015). Volkswagen emission test scandal has created a dramatic consequences having impact on ample number of authorities.

\section{FINDINGS}

3. There have been animated debates surrounding the Volkswagen diesel scandal to find out primary reasons that what factors paved the ground for such scandal to take place and also who was involved in this scandal. This scandal has been reported in a great number of media and news.

\subsection{Participants in Volkswagen Emission Test Scandal}

Firstly, it was reported that nine (9) managers are suspended for being involved in the deception. It is stated by Volkswagen chairman that one of the reason suspended group took this unethical scandal is because of the mindset in some departments of the company which fails to comply the rules (Goodman, McGrath, \& Leah, 2015).

In October 2015, it was stated that the group of employees participated in diesel scandal is small. CEO of Volkswagen announced to the United States lawmakers that for whatever reasons a small group of software engineers embedded the device in cars. The CEO mentioned that he is not aware of exact number of engineers and also this scandal was not corporate decision (Boston, Varnholt, \& Sloat, 2015).

Later, a law firm Jones Day, which is the external investigator of Volkswagen, conducted internal investigation and later revealed that fifty (50) members of staff mostly in Wolfsburg confessed that they were completely aware of emission scandal activities.

Later, news learned that although some Volkswagen engineers and technicians informed their supervisors about emission 
rigging activities in the year 2011, supervisors ignored the alert (Boston, Varnholt, \& Sloat, 2015).

In November 2015, the number of participated managers, technicians, and engineers in the emission test scandal to operate the defeat device is dramatic. There have been various levers in this scandal. It is described that one individual is able to write the codes of defeat device program; on the other hand implementing this program to function with engine and other elements requires more workforces to be involved in (Goodman, McGrath, \& Leah, 2015). Moreover, in accordance with Bode, Volkswagen junior positions were not included in the cheating test, whilst finally it was declared that a great number of managerial and non-managerial the rank and file workforce were involved in diesel emission scandal. The suspended managerial group consists of nine (9) managers from supervisory board, quality control and assurance, engine designers, plant managers, and managers of sub-companies such as Porsche and Audi. EPA has added that approximately hundred (100) million lines of codes are included in each car, whilst in the case of Volkswagen; the defeat device was embedded amongst millions of codes which are definitely far challenging to detect. In addition, there is a possibility that a third-party programmer has written the codes of cheating program, Ricker added (Boston, Varnholt, \& Sloat, 2015).

\subsection{Reasons for Rigging Emission Test}

Martin Winterkorn Volkswagen CEO resigned on September and made announcement to decline that he was aware of diesel scandal. It is believed greatly by a great number of individuals that this unethical scandal occurred because of technology shortcoming prompted Volkswagen to cheat in emission test (Boston, Varnholt, \& Sloat, 2015). On December Hans-Dieter Pötsch chairman of Volkswagen revealed to the public that a group of Volkswagen engineers made decision to rig diesel emission test in 2005 when the united States EPA imposed the toughest emission standards to automobile industry. The significant reason forced them to take this decision at that time was in virtue of technology shortcoming (Boston, Varnholt, \& Sloat, 2015). The engineers were unable to meet the United States emission standards through Volkswagen given time and allocated budget. After specific time span, Volkswagen engineers managed to find a solution to face emission standards, yet they preferred to continue rigging rather than implementing the method. In accordance with Volkswagen chairman public admission, the unethical scandal is not one-off mistake, but it is a whole chain of mistakes taking place without any disruption (Rising \& Sopke, 2015).

One of the other significant reasons fueling Volkswagen deception is unique corporate culture of the company. The culture of Volkswagen is compliance based which employees are obliged to comply with the rules (Goodman, McGrath, \& Leah, 2015). This culture has led to an atmosphere where workforces carry out their tasks under a critically centralized structure. In accordance with this culture, the demand and expectations of the company should be fulfilled regardless of how employees are able to perform the tasks (Goodman, McGrath, \& Leah 2015). According to director of the Center for Automotive Research Ferdinand Dudenhöffe, Volkswagen cultural practices are far different from other automobile manufacturers. The company is autocratic rather than being democratic. The main focus of the company is on roots and Wolfsburg; therefore, there is a noticeable dearth of global thinking. Based on Dudenhöffer, chief positions of Volkswagen might not directly enforced workforces to install defeat device in engines however working environment of
Volkswagen is famous for avoiding dissent and discussion. In Volkswagen human resource practices pave the ground for management positions to tell employees to consider the task again, and if you are not capable to find a solution or to perform your tasks, there are other candidates who are efficient to perform your job. Thus employees of Volkswagen find themselves in a situation where if maintaining job is the concern, there is no choice (Sherk, 2014).

In accordance with one of Volkswagen executive employee, rewarding system of Volkswagen is another reason enforcing employees to prefer keeping quiet about rigging in emission test for a long time even if they preferred to reveal. The bonus system of Volkswagen applies to all workforces from lower positions such as assembly line to higher positions such as chief executives (Elson, Ferrere, \& Goossen, 2015). In Volkswagen rewarding and bonus system, not only employees based on their performance receive bonus but also teams based on their performance and productivity receive bonus. The financial incentive of Volkswagen rewarding system leads employees not to come out with dissenting opinions. In accordance with one of Volkswagen employees, bonus is in commensurate with the amount of remuneration that a staff is paid. In other words, when a Volkswagen staff takes up a greater position, the amount of bonus that staff receives is higher than an assembly line staff that is on lower remuneration (Elson, Ferrere, \& Goossen, 2015).

When Volkswagen cheating in diesel emission test was admitted publically, Bernd Osterloh who is the labor leader of Volkswagen declared that culture and approaches of company is not ethical and appropriate; therefore, some value-based changes should be adapted in the culture of company to allow employees to communicate with higher levels openly regarding any matter within the company, and also to enable employees to share their dissent opinion with their supervisors or chief positions (Sherk, 2014).

Although some people might stick to the idea that Volkswagen scandal took place in virtue of profit maximization, this is in face a misconception. According to the revealed information, it is evident that the primary roots of this deception are fueled from Volkswagen culture and approaches.

\section{ANALYSIS}

Volkswagen scandal has led to a devastating series of critical consequences to its direct and indirect stakeholders. This emission scandal is still under investigation by various authorities with the purpose of identifying actual impacts and coming out with a suitable solutions to finalize the case.

\subsection{Impact of Volkswagen Diesel Scandal}

In the year 2014, Volkswagen was the world's second largest automaker in automobile industry after Toyota Motor Corporation. In the year 2015, Volkswagen admitted rigging in diesel emission test which caused the company to suffer from huge amount of cost burden. Volkswagen has brought in three (3) public relations firms based in United States, Britain, and Germany to assist the company to cope with the crisis. Moreover, Volkswagen has employed the former communications of BMW as a consultant to work 60 hours a week with salary of $\$ 22,000$ per month (Hakim, 2016). Moreover, since this case includes various countries over the world, Volkswagen is required to deal with different international regulations. The primary consequences of this unethical deceptive scandal are listed as follow (Hakim, 2016).

\subsubsection{Threatening People's Health}


By end of 2016, Volkswagen cars with defeat device will have produced additional toxic pollution to directly trigger premature death of roughly sixty (60) individuals merely in the United States. From the year 2008 to 2015, 428,000 Volkswagen and Audi diesel cars pumped out nitrogen oxide forty (40) times more than it was allowed by the Clean Air Act. It is estimated by the researchers that with six (6) years Volkswagen and Audi diesel produced an excess of 36.7 million $\mathrm{kg}$ nitrogen oxide to the environment (Selin, 2015b). Nitrogen oxide is a primary element of particulate and smog matter which paves the ground for various disease namely heart disease, premature death, bronchitis, and respiratory and cardiovascular disease. Researchers have estimated that significant impacts of nitrogen oxide produced by Volkswagen cars endanger 60 human lives from 10 to 20 years prematurely (Selin, 2015a).

It is noted that excess of pollution from Volkswagen vehicles participated directly in thirty-one (31) and thirty-four (34) chronic bronchitis and admission of respiratory and hearth cases respectively in the United States. Additional pollution to the environment will results in 120,000 minor restricted activity day and approximately 210,000 days of less respiratory signs. The sickness of people over six (6) years from 2008 to 2015 will cost United States \$450 million (Kalaugher, 2015).

If Volkswagen declines to recall vehicles with defeat device, from 2015 onwards 140 premature deaths will take place. In addition, health cost of $\$ 840$ million will be caused by the Volkswagen diesel cars (Chue, 2015).

In addition, excess of nitrogen oxide to the natural environment by Volkswagen diesel cars results in acid rains (The Editorial Board, 2016). The acid rains not only have crucial impact on human health bot also have vital destruction on nature and natural resource.

\subsubsection{Slump in Workforce's Bonus}

When rigging in diesel emission test was revealed to the public, sales of Volkswagen was affected. Therefore, Volkswagen in order to cope with crisis, has announced that bonus of chief management will be reduced substantially (Moulson, 2016). Volkswagen said a statement that various models which establish fair and rational solution for all participated parties are being deliberated. As a result, this leads to a considerable diminution of variable remuneration. The reduction in bonus will include management board and also a group of executive positions assisting CEO to operate the company's daily routine. It is said that the bonus of German equivalent of board of directors, which is the supervisory of Volkswagen, would not be reduced except Volkswagen chairman Hans Dieter Poetsch (Moulson, 2016).

\subsubsection{Drop in Volkswagen Sale}

Although Volkswagen diesel scandal has resulted in crucial impact on Volkswagen group brands namely Audi and Skoda, slump in sales of Volkswagen vehicles are far substantial than group brands. The bad reputation of Volkswagen has affected its customer loyalty; therefore, costumers switch from Volkswagen to its competitors which lead to a noticeable drop in sales (Kottasova, 2015). Since 2002, for the first time, in 2015 sales of Volkswagen plunged world-wide substantially in virtue of deceptive scandal. The following figure represents that Volkswagen's sales is continuously plunging in the United States (BBC, 2016; Sky UK, 2016; Waecsh, 2016).

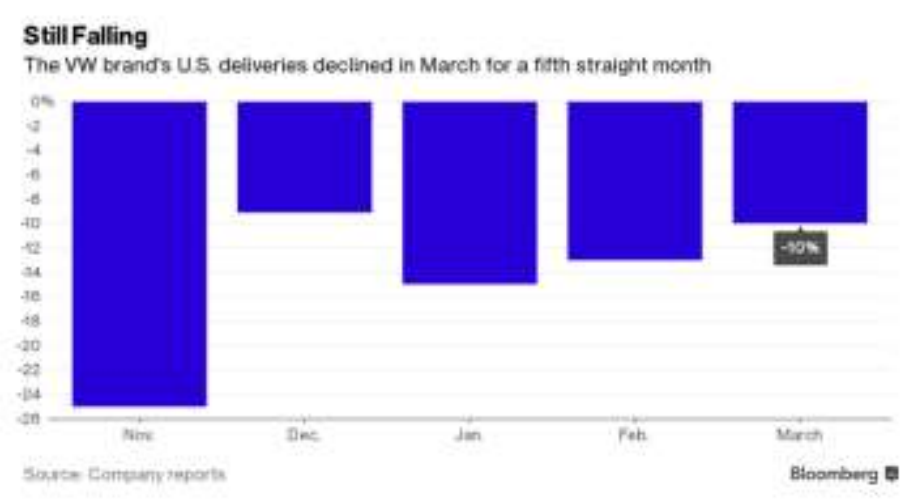

Figure 3.1: Ongoing Drop in Volkswagen Sales Source: (Mittleman, 2016)

\subsubsection{Plunge in Volkswagen Shares}

Unethical practice of Volkswagen led to a dramatic slump in share value. Immediately once Volkswagen scandal was revealed, market showed reaction thus share value of the company dropped by one third. In other words, the emission scandal wiped billion dollars from Volkswagen value (Gomez, 2016). The following figure depicts that Volkswagen stocks price is continuously slumping dramatically in the United States.

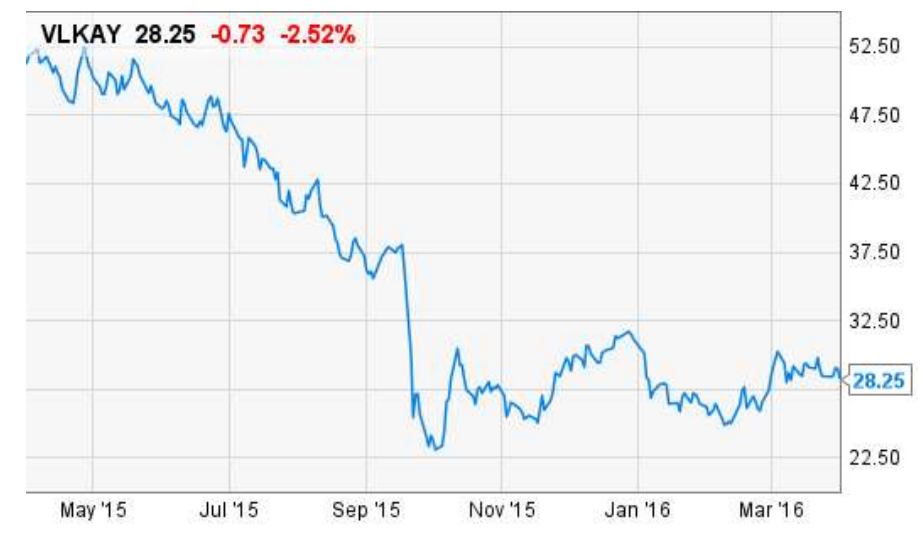

Figure 3.2: Ongoing Drop in Volkswagen Stock Price Source: (Gomez, 2016)

\subsubsection{Creating Hassel for Volkswagen Dealers}

When deceptive emission took place, a package of specific programs with the purpose of assisting retailers to cope with Volkswagen rigging in diesel emission test was provided to Volkswagen dealers (Ausick, 2016). The program includes specific amount of money in form of sales bonus, incentives, or subsidy injected to dealership network struggling with lower sales and profit. The sale of Volkswagen diesel cars, which includes just above 20 percentages of total sales, was stopped. Therefore, dealers are still suffering from thin profit and sluggish sales (Beene, 2016).

On first of October Volkswagen of America with the purpose of relaxing crisis gave extra discretionary funds to Volkswagen dealers to use it in a way they wish. According to Automotive News, the amount of loan varied base on dealer's volume and reached to the highest amount of ten (10) thousand dollar. Volkswagen crisis grew significantly and affected the brand name, whilst dealers were not permitted to sell diesel vehicles. Thus dealers were concern whether the given fund is sufficient for survival or not. The CEO of Volkswagen America stated that further programs will be 
considered for dealers with cash flow, but still specific date is not declared for programs (LaReau \& Ryan, 2015).

A dealer of Volkswagen Steve Kalafer in New Jersey said that the given fund will be utilized to cover the store's operating costs and to boost marketing budget. Kalafer added that millions of dollars have been expended to strengthen this brand, but the scandal is an international deception; therefore, Volkswagen customers, employees, and investment of dealers have been affected. A great number of employees are concern about their job security and they are dissatisfied to encounter with customers suspending them whether they were aware of company's scandal or not (LaReau \& Ryan, 2015).

Another Volkswagen dealer in east coast said that dealers of Volkswagen in the United States are not making money or merely breaking even. Moreover, the dealer adds that the given fund assists to break even or present thin profit.

The other dealer of Volkswagen Bill Wallace in Stuart said that overall customer traffic has reduced significantly and also it is critical to convert shoppers to sales. Therefore, the discretionary fund assists to him to close the deals (LaReau \& Ryan, 2015).

General Manager of Volkswagen Tom Backer in New York said that some amount of the given fund will be utilized primarily to close deals with the owner of diesels cars who are unwilling to get into Volkswagen gasoline cars, whilst the rest of discretionary fund will be given to sales workforces with the purpose of improving their satisfaction and motivation (LaReau \& Ryan, 2015).

\subsection{Current Solutions for Finalizing Volkswagen Scandal}

On 21st April 2016 a judge in California United States declared that Volkswagen has offered a concrete plan which has been supported by United States government agencies and environmental protection agency to solve and finalize the case which Volkswagen cheated in emission test by installing a defeat device in car's engine to game emission standards of EPA in the United States. Almost end of 2015 Volkswagen admitted that in eleven (11) million cars globally the deceptive software has been installed and 600,000 of those cars are on United States roads. Therefore, agreement in principle will be applied to Volkswagen cars in the United States (Sorokanich, 2016). Judge Charles Breyer, U.S. District Court in San Francisco, has proposed a deal which gives options to owners of Volkswagen tow (2) liter diesel cars to fix their cars based on emission standards of the United States or sell back their cars to Volkswagen and cancel their loans (if the cars was purchased with loan). In accordance with the judge, the proposed deal includes considerable compensation for car owners of 2 liter diesels and also offers a fund for proper remediation hardship for any environmental harmful effects caused by Volkswagen cars exceeding pollutions to the environment. Still the details of compensation considered for Volkswagen car owners are not revealed (Goodman, et al., 2016a). Moreover, compensations for 3 liter diesels Volkswagen car owners are still underway. The deliberation of Volkswagen scandal is kept confidential. In accordance with the judge, the proposed agreement is approved and supported by California regulators, California attorney general's office, and the United States Department of Justice respectively. Lawyers stated that it is expected that the Federal Trade Commission (TFC) will accept the proposed deal. TFC recently sued Volkswagen for gaming in clean diesel test (Goodman, et al., 2016a).

The proposed agreement requires more approvals and comments from Volkswagen owners. It is said by the judge that by July Volkswagen will be allowed to defend against a trial. The proposed agreement also consists of a section describing Volkswagen commitment to give further effort to create green car technology (Sorokanich, 2016).

Based on Kelly Blue Book, it costs Volkswagen more than seven (7) billion dollar to buy back the affected vehicles. Therefore, it is estimated that Volkswagen scandal might impose further cost to the company from approximately 6.7 million euros to twofold or even more than the amount (Goodman, et al., 2016a).

Although Volkswagen and Porsche representatives, the Department of Justice, and others have given great efforts to work fourteen (14) hours a day to finalize an appropriate deal to solve Volkswagen deception, yet this case is not finalized yet. The judged announced that June 21 st is the due date for all the involved parties to lodge their proposals before delivering the deal to public (Goodman, et al., 2016a). There is a proposal for Volkswagen emission scandal explained as follow.

It is estimated that a giant amount of money is about to be spent in seeking to penalize Volkswagen for its deception. It is proposed that instead of imposing additional financial burden to punish Volkswagen, there are other ways such as green way to panelize Volkswagen rigging in emission test (Schlanger, 2015). It has been recommended rather than squandering huge amount of money on penalties, it is more favorable to spend this amount of penalty to advance traditional technology. This is a great opportunity to bring out significant changes to automobile industry by requiring Volkswagen to concentrate on electric vehicles. In addition, there is no guaranty that Volkswagen will be able to repair the defeat device. On the other hand, the car owners might prevent to bring their car for fixing compromising performance (Yadigaroglu, 2015). It is rational that EPA releases Volkswagen accountability to recall existing vehicles with defeat device to fix them. Subsequently, EPA has a crucial role to enforce Volkswagen to speed up its roll-out of zero emission cars which emit zero pollutant to the environment. Therefore, zero-emission cars tighten opportunities for cheating in emission tests. Moreover, EPA benefits greatly from zero-emission cars since it is not required to create new complicated and expensive emission test for zero-emission cars. This type of cars has an ample of advantage not only to the EPA and automakers but also to the environment (Yadigaroglu, 2015). Over few years, Zeroemission cars significantly diminish emission which is ten (10) times greater than Volkswagen producing with deceptive device. In practical terms, increasing number of Volkswagen electronic vehicles on roads compensates the emission of Volkswagen cars with deceptive device. Besides, zeroemission cars privilege economy as well by increasing the needs of batteries. In order to fulfill the needs of battery in zero-emission cars, more battery manufacturers are required to be established over the world. High demand for battery manufacturing leads to an investment in lands and also creating jobs for locals in the United States and other regions. Advanced technology will be significantly reducing environment pollution, alleviating regulation of complicated emission standard, and also creating substantial domestic jobs. This is in facet an opportunity for Volkswagen to invest specific amount of money not only to compensate its scandal but also to strengthen its position. The proposed electronic cars have a dramatic role to repurpose the penalized money. According to the recommended proposal, it is evident that this is an ideal solution to finalize case of Volkswagen cheating in emission test (Yadigaroglu, 2015). 


\section{CONCLUSION}

In accordance with findings and analysis under previous sections, Volkswagen deceptive scandal is an overwhelming complicated case having created dramatic hassles for its direct and indirect stakeholders. Albeit Volkswagen cheating in diesel emission test was an unethical action resulting in series of disastrous consequences, the proposal of green punishment is a suitable solution to finalize this case. Electronic cars enable environment protection agencies to save cost and time for finding out new systems for controlling emission tests. Moreover, in this way, Volkswagen is not only penalized but also compensates its scandal appropriately. In conclusion, since this is an ongoing case, there is a chance to lodge the proposal of green punishment to judge to solve the issue in a win-win method.

\section{RECOMMENDATION}

It is evident that the root of this unethical scandal goes back to business culture and structure of the company. Today's business practices are far different from the past practices. The compliance-based business ethics like Volkswagen approach declines to treat employees ethically and also employees face dilemma of loose job or take unethical action; therefore, the company obtains reverse result. The actions of employees have crucial role in success or failure of the company thus it is important to value employees and improve their moral to accomplish tasks ethically. In value-base practices hierarchy does not exist instead the employees work in teams to achieve expected results. Moreover, value-based business ethics promote democracy in the company which means executives have the freedom to voice their complaints to seniors or share their ideas within the company which might result in greater productivity.

In addition, it is obvious that emissions and pollutions are of significant concern to EPA. Thus it is undeniable that EPA new and strict emission standards imposed extreme pressure to automobile industry. EPA has an imperative role to alleviate the extreme pressure on automakers by providing and offering technology and research and development (R\&D) aids. Case of Volkswagen reveals that stringent emission standards resulted in opposite expected outcome with a series of devastating events. Therefore, it is significant to plan for feasible emission standards and also provide technological and R\&D support to automakers to prohibit such case to take place.

All in all, in order to prevent such scandal to occur in future, it is recommended to the companies to value their employees through value-based approach. Besides, EPA is recommended to provide supportive programs to automakers to ensure level of pollutants and emissions are under control.

\section{REFERENCES}

[1] Ausick, P. (2016, March 22). US Volkswagen Dealers Want VW to Pay, 24/7 Wall St. Retrieved from http://247wallst.com/autos/2016/03/22/us-volkswagen-

dealers-want-vw-to-pay/.

[2] BBC, 2016, Volkswagen branded sales drop for first time in 11 years, online retrieved on $8^{\text {th }}$ May 2016 from http://www.bbc.com/news/business-35267164.

[3] Beene, R. (2016, March 31). VW dealers have a lot riding on the make meeting, Automotive News. Retrieved from http://www.autonews.com/article/20160331/RETAIL06/3040 19986/vw-dealers-have-a-lot-riding-on-the-make-meeting.
[4] Boston, W., Varnholt, H., \& Sloat, S. (2015, December 10). Volkswagen Blames 'Chain of Mistakes' for Emissions Scandal, The Wall Street Journal. Retrieved from http://www.wsj.com/articles/vw-shares-up-ahead-ofemissions-findings-1449740759.

[5] Chu, J. (2015, October 28). Study: Volkswagen's emissions cheat to cause 60 premature deaths in U.S., Massachusetts Institute of Technology. Retrieved from http://news.mit.edu/2015/volkswagen-emissions-cheat-cause60-premature-deaths- 1029.

[6] Clothier, M. (2015, September 22). VW's U.S. Chief Apologizes for Diesel Dupe: 'We Screwed Up', BloobBerg L.P. Retrieved from http://www.bloomberg.com/news/articles/2016-05-09/africas-would-be-switzerland-flaunts-economic-prowess-with-wef.

[7] Davenport, C., \& Hakim, D. (2016, January 4). U.S. Sues Volkswagen for Cheating on Emissions Tests, The New York Times. Retrieved from http://www.nytimes.com/2016/01/05/business/vw-suedjustice-department-emissions-scandal.html?_r=0.

[8] Elson, C. M., Ferrere, C. K., \& Goossen, N. J. (2015). The Bug At Volkswagen: Lessons in Co-Determination, Ownership, and Board Structure. Journal of Applied Corporate Finance, 27(4), 36-43.

[9] Gomez, A. (2016, January 4) Volkswagen (VLKAY) Stock Closes Down, U.S. Sales Drop 10\%, TheStreet. Retrieved from http://www.thestreet.com/story/13516097/1/volkswagenvlkay-stock-closes-down-u-s-sales-drop-10.html.

[10] Goodman, McGrath, \& Leah, (2015, Dec. 15). Why Volkswagen Cheated; Intense Ambition and a Rigid Corporate Culture Created the Conditions for Lying at Germany's Biggest Company, Newsweek. Retrieved from http://www.newsweek.com/2015/12/25/why-volkswagencheated-404891.html.

[11] Goodman, McGrath, \& Leah, (2016a, April 24). VOLKSWAGEN, EPA REACH 'CONCRETE PLAN' IN VEHICLE SOFTWARE CHEAT SCANDAL, Newsweek. Retrieved from http://www.newsweek.com/buyback-offerspossible-fix-volkswagen-owners-deal-judge-450789.

[12] Hakin, D. (2016, February 26), VW's Crisis Strategy: Forward, Reverse, U-Turn, The New York Time. Retrieved from

http://www.nytimes.com/2016/02/28/business/international/v ws-crisis-strategy-forward-reverse-u-turn.html.

[13]Kalaugher, L. (2015, October 29) Excess emissions from Volkswagen diesels could cause 59 early US deaths, IOP Publishing. Retrieved from http://environmentalresearchweb.org/cws/article/news/63032.

[14] Klier, T., \& Linn, J. (2016). Comparing US and EU Approaches to Regulating Automotive Emissions and Fuel Economy.

[15]Kottasova, I. (2015, December 4). Volkswagen's sales are collapsing, Cable News Network. Retrieved from http://money.cnn.com/2015/12/04/news/companies/volkswage n-sales-down/. 
[16] LaReau, J., \& Ryan, B. (2015, October 12). As crisis grows, Volkswagen dealers fear cash won't be enough, Automotive News. Retrieved from http://www.autonews.com/article/20151012/OEM/310129960 /as-crisis-grows-volkswagen-dealers-fear-cash-wont-beenough.

[17] Le Page, M. (2015). How did Volkswagen rig emissions tests?. New Scientist, 227(3041), 11.

[18] Mittelman, M. (2016, May 3). Sales Drop Is Smallest Since December, BloobBerg L.P. Retrieved from http://www.bloomberg.com/news/articles/2016-05-

03/volkswagen-brand-s-u-s-sales-drop-is-smallest-sincedecember.

[19] Moulson, G. (2016, April 13). Volkswagen says its managers' bonuses will be cut following the automaker's diesel emissions scandal, U.S. News \& World Report. Retrieved from http://www.usnews.com/news/business/articles/2016-0413/volkswagen-to-cut-managers-bonuses-following-dieselscandal.

[20] Rising, D., \& Sopke, K. (2015, December 10). Volkswagen engineers worked on emissions cheating in U.S. as early as 2005, MaineToday Media. Retrieved from http://www.pressherald.com/2015/12/10/volkswagenengineers-began-working-on-cheat-in-2005-for-u-s-market/.

[21]Schlanger, Z. (2015, December 17). LETTER FROM ELON MUSK: VOLKSWAGEN'S CHEATING SCANDAL PUNISHMENT SHOULD BE TO MAKE ZERO-EMISSION CARS, Newsweek. Retrieved from http://www.newsweek.com/letter-elon-musk-volkswagenscheating-scandal-punishment-should-be-make-zero-406633.

[22] Selin, N., E. (2015b September 30). The company's deception could exceed $\$ 100$ million in costs from health damages, $\quad$ Fortune. $\quad$ Retrieved from http://fortune.com/2015/09/30/volkswagen-diesel-scandalconsequences/.

[23] Selin, N., E. (2015a, September 30). Volkswagen emissions cheating caused $\$ 100$ million in health costs, according to analysis, Grist. Retrieved from http://grist.org/climate-energy/volkswagen-emissionscheating-caused-100-million-in-health-costs-according-toanalysis/.

[24] Sherk, J. (2014). Expand Employee Participation in the Workplace. The Heritage Foundation, March, 13.

[25] Sky UK, 2016, VW Sales Fall For First Time In 11 Years, online retrieved on $8^{\text {th }}$ May 2016 from http://news.sky.com/story/1619342/vw-sales-fall-for-firsttime-in-11-years.

[26] Sorokanich, B. (2016, April 21). VW Agrees to Buy Back U.S. Diesel Vehicles Affected by TDI Emissions Cheat, Road and Track. Retrieved from http://www.roadandtrack.com/new-cars/cartechnology/news/a28916/vw-tdi-emissions-settlement/.

[27] The Editorial Board, (2016, February 16). Beyond the Emissions Test at VW, The New York Time. Retrieved from http://www.nytimes.com/2016/02/17/opinion/beyond-theemissions-test-at-vw.html.

[28] Waecsh, M., H. (2016, January 8). Volkswagen Sales Drop for First Time in 13 Years, Dow Jones. Retrieved from http://www.wsj.com/articles/volkswagen-group-sales-dropfor-first-time-in-13-years-1452275074.

[29] Yadigaroglu, I., (2015, December 18). A GREEN WAY TO PUNISH CHEATING VOLKSWAGEN, Newsweek. Retrieved from http://www.newsweek.com/green-waypunish-cheating-volkswagen-406905. 